\title{
Proteomic and microRNA-omic profiles and potential mechanisms of dysfunction in pancreatic islet cells primed by inflammation
}

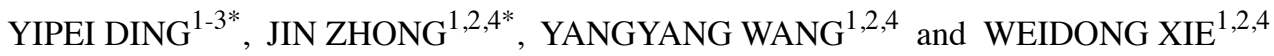 \\ ${ }^{1}$ Shenzhen Key Lab of Health Science and Technology, Institute of Biopharmaceutical and Health Engineering, \\ Shenzhen International Graduate School, Tsinghua University, Shenzhen, Guangdong 518055; ${ }^{2}$ State Key Laboratory of \\ Chemical Oncogenomics, Shenzhen International Graduate School, Tsinghua University, Shenzhen, Guangdong 518055; \\ ${ }^{3}$ Department of Chemistry, Tsinghua University, Beijing 100084; ${ }^{4}$ Open FIESTA Center, Shenzhen \\ International Graduate School, Tsinghua University, Shenzhen, Guangdong 518055, P.R. China
}

Received April 13, 2020; Accepted October 26, 2020

DOI: $10.3892 /$ etm.2020.9554

\begin{abstract}
Diabetes is an inflammatory disease that induces pancreatic islet dysfunction. However, to the best of our knowledge, the potential underlying molecular mechanisms of this inflammatory process remains unknown. The present study investigated microRNA (miRNA/miR) and protein expression profiles through proteomics and miRNA-omics. Lipopolysaccharide-induced macrophage cell medium (LRM) was used to stimulate inflammation in mouse Beta-TC- 6 islet cells. Protein analysis revealed that 87 proteins were upregulated and 42 proteins were downregulated in LRM-treated Beta-TC-6 cells compared with control cells. Additionally, miRNA analysis revealed that 11 miRNAs were upregulated, while 28 miRNAs were downregulated in LRM-treated Beta-TC-6 cells compared with control cells. Islet cells exposed to inflammation exhibited markedly downregulated protein levels of transcription factor MafA, pancreatic and duodenal homeobox 1, paired box 6 , homeobox protein $\mathrm{Nkx}-2.2$, synaptosomal-associated protein 25, glucagon and insulin-2, while the expression of miR-146a-5p and miR-21a-5p were upregulated. It was also determined that upregulated miR-146a-5p and miR-21a-5p levels may be mediated by NF- $\kappa \mathrm{B}$ activation. The downregulation of islet functional factor mRNA was partially reversed by treating islet cells with an inhibitor of miR-21a-5p. However, treatment with an miR-146a-5p inhibitor did not
\end{abstract}

Correspondence to: Dr Weidong Xie, Shenzhen Key Lab of Health Science and Technology, Institute of Biopharmaceutical and Health Engineering, Shenzhen International Graduate School, Tsinghua University, L412 Tsinghua Campus, 2279 Lishui Road, Shenzhen, Guangdong 518055, P.R. China

E-mail: xiewd@sz.tsinghua.edu.cn

${ }^{*}$ Contributed equally

Key words: diabetes, islets, inflammation, microRNA-146a-5p, microRNA-21a-5p, micro-omics, proteomics exert the same effect. Overall, the present study determined the molecular profiles of islet cell inflammation based on proteomics and miRNA-omics, and indicated that the proteins and miRNAs with altered expressions may form a large network that serves a role in islet dysfunction. Particularly, miR-21a-5p upregulation in response to inflammation may contribute to islet cell dysfunction. However, how these miRNAs regulated the expression of certain mRNAs and proteins in islet cell inflammation requires further investigation.

\section{Introduction}

Among adults in China, the estimated overall prevalence of diabetes and pre-diabetes was 10.9 and $35.7 \%$ in 2013, respectively (1). Although diabetes causes severe complications and has been one of the most important public health problems worldwide, its undetermined etiology means that the prevention and treatment of the disease remains challenging (2).

Diabetes is an inflammatory disease (3), in which pancreatic islet cells are usually in a state of inflammation triggered by active macrophages or lymphocytes $(4,5)$. Leukocyte invasion and activation in islet cells may inhibit insulin production or cause islet apoptosis (6). However, to the best of our knowledge, the molecular targets and main contributors, as well as the reason inflammation affects islet function, remains unknown.

MicroRNAs (miRNAs/miRs) target the 3'-untranslated region of mRNAs and regulate protein translation (7). miRNAs are emerging as important tools for understanding the molecular mechanisms and etiology of various diseases (8). miRNAs serve important roles in the dialogue between immune or inflammatory systems and pancreatic endocrine cells (9). However, few systematic investigations of this process have been conducted.

The present study performed proteomics and miRNA-omics to investigate pancreatic islet cell inflammation. Based on systematic changes of proteins and miRNAs, a network of molecules involved in islet inflammation was constructed to determine the potential molecular mechanisms underlying islet inflammation and diabetes. 


\section{Materials and methods}

Cell culture. Cell culture, inflammation induction and sample collection were performed using methods as previously described (10). RAW264.7 and Beta-TC-6 cells were provided by the Cell Resource Centre of the Shanghai Institutes for Biological Science, Chinese Academy of Sciences, China. Each cell line was cultured in high glucose DMEM (Gibco; Thermo Fisher Scientific, Inc.) supplemented with 10\% FBS (PAN Biotech UK, Ltd.) and 1\% penicillin-streptomycin antibiotics (Gibco; Thermo Fisher Scientific, Inc.). The cells were incubated in a humidified atmosphere with $5 \% \mathrm{CO}_{2}$ at $37^{\circ} \mathrm{C}$. The cells were seeded into 6 -well plates at a density of $2.5 \times 10^{5}$ cells/well.

Inflammation was induced in RAW264.7 cells by adding $2 \mu \mathrm{g} / \mathrm{ml}$ lipopolysaccharide (LPS; cat. no. L4391; Sigma-Aldrich; Merck KGaA) after $12 \mathrm{~h}$ of incubation at $37^{\circ} \mathrm{C}$. Subsequently, the supernatant of LPS-induced RAW264.7 cell medium (LRM) was collected. LRM usually markedly increases levels of IL-1A ( 20 pg/ml), IL-6 ( $\sim 800 \mathrm{pg} / \mathrm{ml})$ and TNF- $\alpha(\sim 1,200 \mathrm{pg} / \mathrm{ml})$ in cell medium (10). In Beta-TC- 6 cells, inflammation was induced for $24 \mathrm{~h}$ by adding a mixture of LRM and common medium (DMEM with $10 \%$ FBS) at a ratio of $1: 3(\mathrm{v}: \mathrm{v})$.

To obtain protein samples, Beta-TC-6 cells in the 6-well plates were washed with ice-cold PBS twice. A $200 \mu 1$ aliquot of cell lysis buffer ( $50 \mathrm{mM}$ Tris-HCl, $4 \mathrm{M}$ urea and $1 \%$ Triton X-100; $\mathrm{pH} 8.0$ ) was subsequently added to the wells. Cell samples were transferred into $1 \mathrm{ml}$ Eppendorf tubes for further protein extraction and immediately stored at $-80^{\circ} \mathrm{C}$ for cell protein assays.

To obtain RNA samples, Beta-TC-6 cells in the 6-well plates were collected at $24 \mathrm{~h}$ after LRM induction. Cells were washed twice with ice-cold PBS and $1 \mathrm{ml}$ TRIzol ${ }^{\circledR}$ (Invitrogen; Thermo Fisher Scientific, Inc.) was added to the wells. Subsequently, RNA extraction was performed in $1 \mathrm{ml}$ Eppendorf tubes according to the instruction manual of the TRIzol ${ }^{\circledR}$ kit

Protein assay. Protein extraction, digestion, isobaric tags for relative and absolute quantitation (iTRAQ) labeling and liquid chromatography with tandem mass spectrometry (MS/MS) were performed in LRM-treated Beta-TC- 6 cells and untreated control cells after $24 \mathrm{~h}$ of LRM treatment at $37^{\circ} \mathrm{C}$ by PTM Biolab LLC as previously described (11). Raw data from MS/MS were processed for peptide identification by searching the Maxquant database (12), and the resultant peptides were assembled as proteins as previously described (13). The ion intensity of the iTRAQ reporter in each sample was used for quantitation analysis and comparison (14). Proteins with a fold expression change $>1.5$ for upregulation or $<0.67$ for downregulation between LRM-treated Beta-TC- 6 cells and LRM-untreated control cells were selected for further analysis.

Protein-protein interaction analysis was performed using the Search Tool for the Retrieval of Interacting Genes/Proteins database (v10; http://string-db.org/) as previously described (15). Protein signaling pathways were annotated using the Kyoto Encyclopedia of Genes and Genomes (KEGG) database (https://www.kegg. jp/kegg/pathway.html). A two-tailed Fisher's exact test was used to test the enrichment of the altered proteins against all identified proteins. $\mathrm{P}<0.05$ was considered to indicate a statistically significant difference.

RNA isolation, library preparation and sequencing. RNA isolation, library preparation and sequencing were performed in LRM-treated Beta-TC-6 cells and untreated control cells after $24 \mathrm{~h}$ of LRM treatment at $37^{\circ} \mathrm{C}$ by Novogene Co., Ltd. as previously described (16). After total RNA was extracted, RNA degradation and contamination were monitored on $1 \%$ agarose gels. RNA purity was checked using the NanoPhotometer ${ }^{\circledR}$ spectrophotometer (Implen $\mathrm{GmbH}$ ) and RNA concentrations were measured using a Qubit ${ }^{\circledR}$ RNA assay kit on a Qubit ${ }^{\circledR} 2.0$ Flurometer (each, Thermo Fisher Scientific, Inc.). RNA integrity was assessed using the RNA Nano 6000 assay kit and the Agilent Bioanalyzer 2100 system (each, Agilent Technologies, Inc.).

Total RNA in quantities of $3 \mu \mathrm{g}$ per sample was used as input material for the small RNA library. Sequencing libraries were generated using the NEBNext ${ }^{\circledast}$ Multiplex Small RNA Library Prep Set for Illumina ${ }^{\circledR}$ (New England BioLabs, Inc.) according to the manufacturer's protocol. Index codes were added to attribute sequences to each sample.

The clustering of index-coded samples was performed on a cBot Cluster Generation system (Illumina, Inc.) using the TruSeq SR Cluster kit v3-cBot-HS (Illumina, Inc.) according to the manufacturer's protocol. Following cluster generation, library preparations were sequenced on an Illumina HiSeq 2500/2000 platform (Illumina, Inc.) and 50 bp single-end reads were generated.

Data analysis. Raw data (raw reads) in the fastq format were first processed using custom perl and python scripts. During this step, clean data (clean reads) were obtained by removing those containing poly-N with 5 ' adapter contaminants, without the 3 ' adapter or the insert tag. Those containing poly A, T, G or $\mathrm{C}$, and low-quality reads from raw data were also removed. At the same time, Q20, Q30 and GC-content of the raw data were calculated. Subsequently, a range of length was selected from the clean reads to perform all downstream analyses. The small RNA tags were mapped to a reference sequence using Bowtie (bowtie-0.12.9; http://bowtie-bio.sourceforge.net/index.shtml) without mismatch to analyze their expression and distribution on the reference (17). Mapped small RNA tags were used to identify known miRNAs. miRbase 20.0 was used as reference (http://www.mirbase.org). Modified mirdeep2 software (mirdeep2_0_0_5; https://github.com/rajewsky-lab/mirdeep2) and srna-tools-cli (http://srna-tools.cm p.uea.ac.uk/) were used to obtain the potential miRNAs and draw the resultant secondary structures (18). Custom scripts were used to obtain the miRNA counts as well as base bias (on the first position of the identified miRNA with a certain length and on each position of all identified miRNAs), respectively. miRNA expression levels were estimated in terms of transcript per million using the following criteria (19): Normalization formula: Normalized expression=mapped read count/total reads $x 1,000,000$. For samples without biological replicates, differential expression analysis of two samples was performed using the DEGseq (2010) R package (version 1.2.2) (20). P-values were adjusted using the q-value (21). A q-value 
Table I. miRNA primers for reverse transcription-quantitative PCR.

\begin{tabular}{ll}
\hline miRNAs & \multicolumn{1}{c}{ Primer sequence (5' to 3') } \\
\hline mmu-miR-21a-5p & F: TCGCCCGTAGCTTATCAGACT \\
R: CAGAGCAGGGTCCGAGGTA \\
mmu-miR-146a-5p & F: CTGCCGCTGAGAACTGAATT \\
& R: CAGAGCAGGGTCCGAGGTA \\
U6 snRNA & F: CGCTTCGGCAGCACATATAC \\
& R: TTCACGAATTTGCGTGTCATC
\end{tabular}

F, forward; R, reverse.

$<0.01$ and $\log 2$ (fold change) $>1$ was set as the threshold for significant differential expression by default. miRNAs with $\log 2$.fold change values $\geq 0.5$ or $\leq-0.5$ between LRM-treated Beta-TC-6 cells and control cells were selected for further analysis. Taking into account abundance and fold changes in miRNA expression, miRNAs with an abundance value $>1,000$ and a fold change $>2$ were selected for further reverse transcription-quantitative PCR (RT-qPCR) validation.

$N F-\kappa B$ inhibition. As the NF- $\kappa B$ signaling pathway serves an important role in the activation of inflammation (22), the present study used an NF- $\mathrm{KB}$ inhibitor to investigate whether NF- $\kappa \mathrm{B}$ mediated miRNA changes. After Beta-TC- 6 cells were incubated for $12 \mathrm{~h}$, inflammation was induced by LRM as aforementioned. Simultaneously, $10 \mu \mathrm{M}$ NF- $\kappa \mathrm{B}$ inhibitor (MLN120B; MedChemExpress) was added. Following treatment with MLN120B for $12 \mathrm{~h}$ at $37^{\circ} \mathrm{C}$, total RNA was extracted from Beta-TC- 6 cells for miRNA or mRNA detection according to the aforementioned protocol.

miRNA transfection. The present study used miR-21a-5p and miR-146a-5p inhibitors to determine whether these miRNAs contributed to islet dysfunction as previously described (10). miRNA inhibitors (miR-21a-5p inhibitor, 5'-UCAACAUCA GUCUGAUAAGCUA-3'; miR-146a-5p inhibitor, 5'-AACCCA UGGAAUUCAGUUCUCA-3') and negative inhibitor control (5'-CAGUACUUUUGUGUAGUACAAA-3') were synthesized by Guangzhou RiboBio Co., Ltd. Beta-TC-6 cells were seeded at a density of $2.5-5 \times 10^{5}$ per well into 6-well-plates and incubated for $12 \mathrm{~h}$ at $37^{\circ} \mathrm{C}$. Cells were transferred to fresh medium (DMEM with 10\% FBS) and transfected with miRNA inhibitors at a concentration of $60 \mathrm{pmol} / \mathrm{well}$ using Lipofectamine ${ }^{\circledR} 3000$ (Invitrogen; Thermo Fisher Scientific, Inc.) according to the manufacturer's protocol. After 6-12 h of transfection at $37^{\circ} \mathrm{C}$, inflammation was induced for $24 \mathrm{~h}$ at $37^{\circ} \mathrm{C}$ by LRM as aforementioned. Total RNA was extracted from cells for miRNA or mRNA detection according to the aforementioned protocol after $24 \mathrm{~h}$ of inflammation induction.

$R T-q P C R$. miRNA and mRNA qPCR was performed as previously described $(10,23)$. To determine the expression of miR-21a-5p and miR-146a-5p in Beta-TC-6 cells, an miRNA assay kit (Shanghai GenePharma Co., Ltd.) was used according to the manufacturer's protocol. The U6 gene was utilized as an internal control for normalization. The primers used for miRNA analysis are provided in Table I. RT was conducted using a DNA Engine H Peltier Thermal Cycler (Bio Rad Laboratories, Inc.) under the following temperature protocol: $25^{\circ} \mathrm{C}$ for $30 \mathrm{~min}, 42^{\circ} \mathrm{C}$ for $30 \mathrm{~min}$ and $85^{\circ} \mathrm{C}$ for $5 \mathrm{~min}$, followed by a holding step at $4^{\circ} \mathrm{C}$. The primers for the mRNA assay were according to PrimerBank (https://pga.mgh. harvard.edu/primerbank/) and synthesized by Genewiz, Inc. (Table II). Actin was used as an internal control for normalization. RT of mRNA samples extracted from Beta-TC-6 cells was performed using a PrimeScript ${ }^{\mathrm{TM}}$ 1st Strand cDNA Synthesis kit (Takara Biotechnology Co., Ltd.) according to the manufacturer's protocol. RT was conducted using a DNA Engine $\mathrm{H}$ Peltier Thermal Cycler with the following conditions: $16^{\circ} \mathrm{C}$ for $30 \mathrm{~min}, 42^{\circ} \mathrm{C}$ for $30 \mathrm{~min}$ and $85^{\circ} \mathrm{C}$ followed by a hold step at $4^{\circ} \mathrm{C}$. All qPCR assays including miRNAs and mRNAs were performed using SYBR ${ }^{\circledR}$ Green I dye (Takara Biotechnology Co., Ltd.) according to the manufacturer's protocol $\left(95^{\circ} \mathrm{C}\right.$ for $3 \mathrm{~min}$, followed by 40 cycles of $95^{\circ} \mathrm{C}$ for $12 \mathrm{sec}$ and $60^{\circ} \mathrm{C}$ for $40 \mathrm{sec}$ ) using an ABI PRISM 7300 Real-time PCR system (Applied Biosystems; Thermo Fisher Scientific, Inc.). To determine the unicity of the transcript analysis, dissociation curve analysis of amplification products was performed and it was confirmed that only one peak (PCR amplification product) was observed in each curve. The fold change was calculated using the $2^{-\Delta \Delta \mathrm{Cq}}$ method of relative quantification (24). All experiments were performed in triplicate.

Statistical analysis. Statistical analysis was performed using GraphPad Prism 5 software (version 5.01; GraphPad Software, Inc.) as previously described (10). Data are presented as the mean $\pm \mathrm{SD}$. A two tailed unpaired $t$ test was used to evaluate the statistical significance of data. $\mathrm{P}<0.05$ was considered to indicate a statistically significant difference.

\section{Results}

Protein assay. Based on the results of proteomics, proteins with a fold expression change $>1.5$ for upregulation or $<0.67$ for downregulation between LRM-treated Beta-TC- 6 cells and control cells were selected for further analysis. It was revealed that 87 proteins were upregulated and 42 proteins were downregulated in LRM-treated Beta-TC-6 cells compared with control cells (Fig. 1).

Protein-protein interaction and KEGG pathway analyses (Figs. 2 and 3) of the upregulated proteins indicated that various immune and inflammatory signaling pathways may be activated, including 'antigen processing and presentation', 'NF-kappa B signaling pathway', 'cell adhesion molecules', 'Jak-STAT signaling pathway' and 'hepatitis C and B' (Fig. 2B). However, analysis of the downregulated proteins indicated that islet function-related certain signaling pathways may be attenuated, including 'maturity onset diabetes of the young', 'insulin secretion' and 'type II diabetes mellitus' (Fig. 3B). The downregulated proteins included transcription factor MafA (Mafa), pancreatic and duodenal homeobox 1 (Pdx-1), paired box 6 (Pax-6), homeobox protein Nkx-2.2 (Nkx-2.2), synaptosomal-associated protein 25 (Snap25), glucagon (Gcg) 
Table II. mRNAs primers for reverse transcription-quantitative PCR.

\begin{tabular}{|c|c|c|c|}
\hline Gene name & NCBI accession No. & Primer sequence ( $5^{\prime}$ to $\left.3^{\prime}\right)$ & Size $(b p$ \\
\hline Mouse IL-1A & NP_034684 & $\begin{array}{l}\text { Forward: TCTGCCATTGACCATCTC } \\
\text { Reverse: ATCTTCCCGTTGCTTGAC }\end{array}$ & 182 \\
\hline Mouse TNF- $\alpha$ & NP_038721 & $\begin{array}{l}\text { Forward: GGGCTTCCAGAACTCCA } \\
\text { Reverse: GCTACAGGCTTGTCACTCG }\end{array}$ & 213 \\
\hline Mouse Nkx-2.2 & NP_035049 & $\begin{array}{l}\text { Forward: CCGGGCGGAGAAAGGTATG } \\
\text { Reverse: CTGTAGGCGGAAAAGGGGA }\end{array}$ & 156 \\
\hline Mouse Pdx-1 & NP_032840 & $\begin{array}{l}\text { Forward: CCCCAGTTTACAAGCTCGCT } \\
\text { Reverse: CTCGGTTCCATTCGGGAAAGG }\end{array}$ & 177 \\
\hline Mouse Gcg & NP_032126 & $\begin{array}{l}\text { Forward: TTACTTTGTGGCTGGATTGCTT } \\
\text { Reverse: AGTGGCGTTTGTCTTCATTCA }\end{array}$ & 149 \\
\hline Mouse Pax-6 & NP_001231129 & $\begin{array}{l}\text { Forward: GCAGATGCAAAAGTCCAGGTG } \\
\text { Reverse: CAGGTTGCGAAGAACTCTGTTT }\end{array}$ & 285 \\
\hline Mouse Snap25 & NP_035558 & $\begin{array}{l}\text { Forward: CAACTGGAACGCATTGAGGAA } \\
\text { Reverse: GGCCACTACTCCATCCTGATTAT }\end{array}$ & 177 \\
\hline Mouse Mafa & NP_919331 & $\begin{array}{l}\text { Forward: AGGAGGGTCATCCGACTG } \\
\text { Reverse: CTTCTCGCTCCAGAATGTG }\end{array}$ & 113 \\
\hline Mouse Ins2 & NP_001172013 & $\begin{array}{l}\text { Forward: GCTTCTTCTACACACCCATGTC } \\
\text { Reverse: AGCACTGATCTACAATGCCAC }\end{array}$ & 147 \\
\hline Mouse Actin & NP_031419 & $\begin{array}{l}\text { Forward: GTGACGTTGACATCCGTAAAGA } \\
\text { Reverse: GCCGGACTCATCGTACTCC }\end{array}$ & 245 \\
\hline
\end{tabular}

Nkx-2.2, homeobox protein Nkx-2.2; Pdx-1, pancreatic and duodenal homeobox 1; Pax-6, paired box 6; Snap25, synaptosome-associated protein 25; Mafa, transcription factor MafA; Ins2, insulin-2.

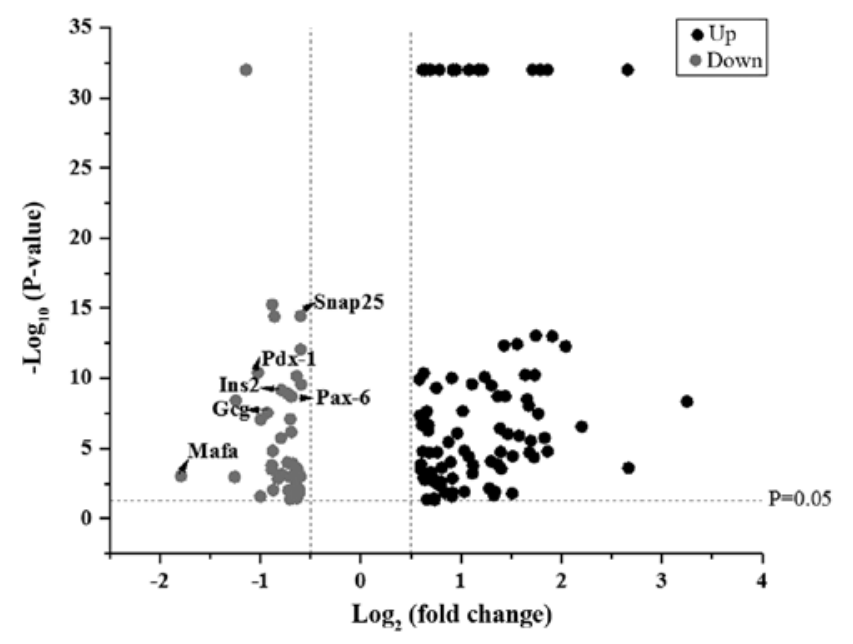

Figure 1. Volcano plot of upregulated and downregulated proteins in lipopolysaccharide-induced RAW264.7 cell medium-treated Beta-TC-6 cells compared with controls. Snap25, synaptosome-associated protein 25; Pdx-1, pancreatic and duodenal homeobox 1; Ins2, insulin-2; Pax-6, paired box 6; Gcg, glucagon; Mafa, transcription factor MafA; up, upregulated; down, downregulated.

and insulin-2 (Ins2). These proteins may therefore mediate islet dysfunction.

miRNA expression profile. Based on the results of the miRNA assay, miRNAs with $\log 2$. Fold change values $\geq 0.5$ or $\leq-0.5$ between LRM-treated Beta-TC-6 cells and control cells were selected for further analysis. It was revealed that 11 miRNAs were upregulated and 28 miRNAs were downregulated (Fig. 4).

Taking into account abundance and fold changes in miRNA expression, miRNAs with an abundance value $>1,000$ and a fold change $>2$ were selected for further validation. Therefore, only miR-146a-5p and miR-21a-5p were appropriate for further analysis.

Validation of miRNAs and protein-matched gene functions. The present study selected miR-21a-5p and miR-146a-5p for further investigation as aforementioned. The results of RT-qPCR indicated that the expression of miR-21a-5p and miR-146a-5p, and inflammatory factors IL-1A and TNF- $\alpha$ were significantly increased following inflammation induction (Fig. 5A-C; all, P<0.01). Additionally, miR-146a-5p was further upregulated when compared with miR-21a-5p $(\sim 6$-fold; $\mathrm{P}<0.01)$. Following treatment with the $\mathrm{NF}-\kappa \mathrm{B}$ inhibitor MLN120B, the expression of miR-21a-5p and miR-146a-5p were significantly decreased $(\mathrm{P}<0.05$ and $\mathrm{P}<0.01$, respectively; Fig. 5D and E). Furthermore, levels of IL-1A and TNF- $\alpha$ were significantly decreased following the same treatment (each, $\mathrm{P}<0.01$; Fig. $5 \mathrm{~F}$ ). The results indicated that inflammation activation by $\mathrm{NF}-\kappa \mathrm{B}$ may contribute to the upregulation of miR-21a-5p and miR-146a-5p expression. 
A

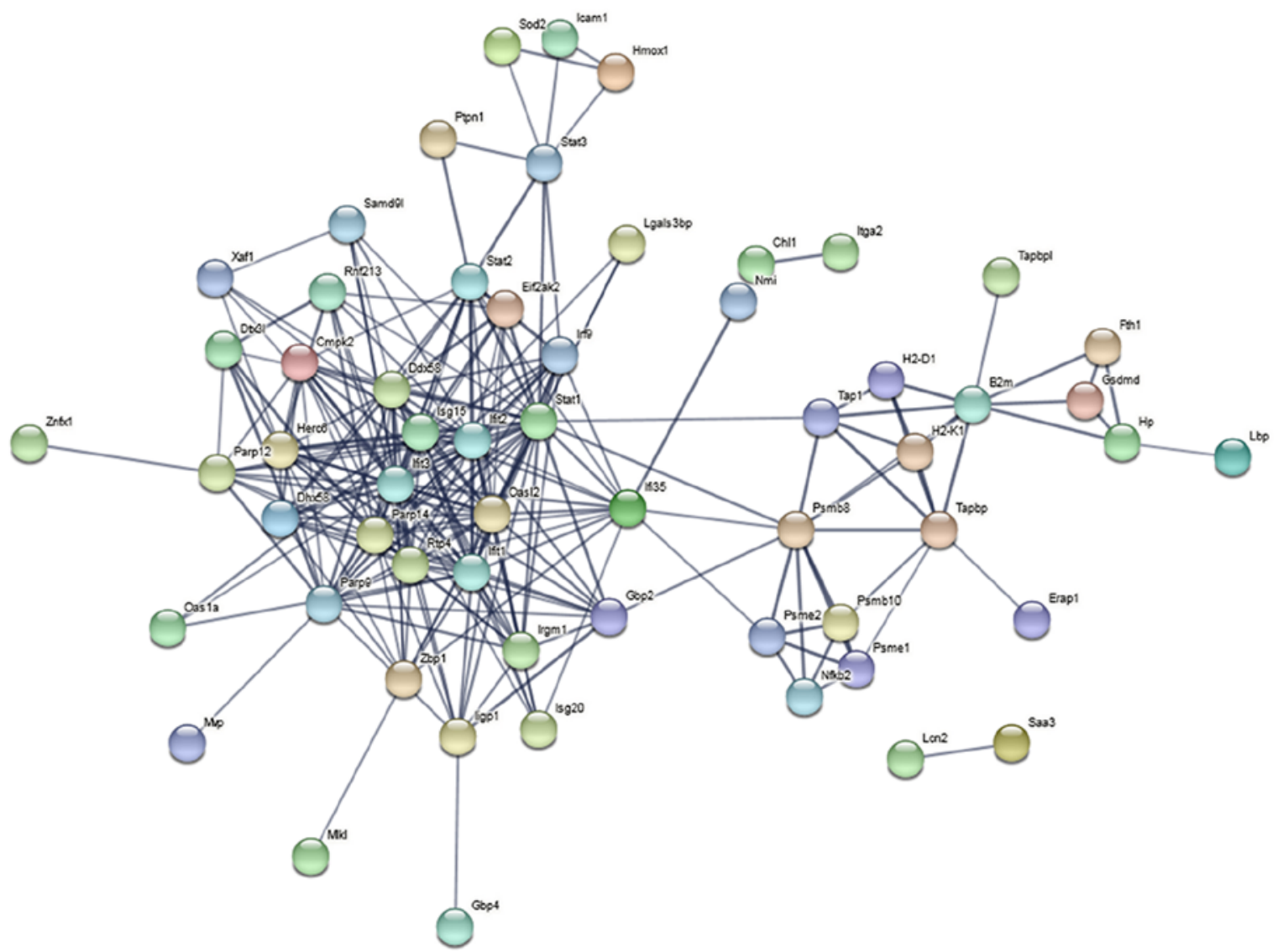

$\mathrm{B}$

\begin{tabular}{|c|c|c|c|}
\hline \multicolumn{4}{|c|}{ KEGG pathways } \\
\hline Pathway & Description & \multicolumn{2}{|c|}{ Count in gene set False discovery rate } \\
\hline$\underline{\mathrm{mmu} 05168}$ & Herpes simplex infection & 11 of 202 & $8.52 e-08$ \\
\hline$\underline{\mathrm{mmu} 04612}$ & Antigen processing and presentation & 8 of 78 & $9.66 e-08$ \\
\hline$\underline{\mathrm{mmu} 05160}$ & Hepatitis C & 8 of 133 & $3.23 e-06$ \\
\hline$\underline{\mathrm{mmu} 04217}$ & Necroptosis & 8 of 158 & $8.51 e-06$ \\
\hline$\underline{\mathrm{mmu} 05164}$ & Influenza A & 8 of 165 & $8.92 e-06$ \\
\hline$\underline{\mathrm{mmu} 04621}$ & NOD-like receptor signaling pathway & 8 of 164 & $8.92 e-06$ \\
\hline$\underline{\text { mmu05162 }}$ & Measles & 7 of 132 & $2.07 e-05$ \\
\hline$\underline{\mathrm{mmu} 05167}$ & Kaposi's sarcoma-associated herpesvirus infection & 8 of 203 & $2.61 e-05$ \\
\hline$\underline{\text { mmu05165 }}$ & Human papillomavirus infection & 9 of 335 & 0.00011 \\
\hline$\underline{\text { mmu05169 }}$ & Epstein-Barr virus infection & 7 of 205 & 0.00023 \\
\hline$\underline{\mathrm{mmu} 03050}$ & Proteasome & 4 of 45 & 0.00043 \\
\hline mmu05203 & Viral carcinogenesis & 6 of 199 & 0.0014 \\
\hline$\underline{\mathrm{mmu} 04380}$ & Osteoclast differentiation & 5 of 122 & 0.0014 \\
\hline$\underline{\text { mmu04145 }}$ & Phagosome & 5 of 165 & 0.0046 \\
\hline mmu04064 & NF- $\mathrm{KB}$ signaling pathway & 4 of 93 & 0.0046 \\
\hline mmu05161 & Hepatitis B & 4 of 143 & 0.0193 \\
\hline$\underline{\mathrm{mmu} 04622}$ & RIG-I-like receptor signaling pathway & 3 of 68 & 0.0193 \\
\hline$\underline{\text { mmu05416 }}$ & Viral myocarditis & 3 of 76 & 0.0237 \\
\hline mmu04630 & Jak-STAT signaling pathway & 4 of 161 & 0.0237 \\
\hline$\underline{\mathrm{mmu} 04514}$ & Cell adhesion molecules (CAMs) & 4 of 158 & 0.0237 \\
\hline$\underline{\mathrm{mmu} 05323}$ & Rheumatoid arthritis & 3 of 81 & 0.0241 \\
\hline$\underline{\text { mmu05200 }}$ & Pathways in cancer & 7 of 522 & 0.0250 \\
\hline$\underline{\mathrm{mmu} 04933}$ & AGE-RAGE signaling pathway in diabetic complications & 3 of 100 & 0.0387 \\
\hline mmu04066 & HIF-1 signaling pathway & 3 of 102 & 0.0391 \\
\hline$\underline{\mathrm{mmu} 05145}$ & Toxoplasmosis & 3 of 107 & 0.0427 \\
\hline$\underline{\text { mmu04668 }}$ & TNF signaling pathway & 3 of 108 & 0.0427 \\
\hline$\underline{\text { mmu04650 }}$ & Natural killer cell mediated cytotoxicity & 3 of 111 & 0.0435 \\
\hline \multirow[t]{2}{*}{$\underline{\mathrm{mmu} 04216}$} & Ferroptosis & 2 of 40 & 0.0483 \\
\hline & & & (less ...) \\
\hline
\end{tabular}

Figure 2. Protein-protein interaction analysis among upregulated proteins. (A) Protein-protein interaction and (B) signaling pathway analyses of upregulated proteins. KEGG, Kyoto Encyclopedia of Genes and Genomes. 
A

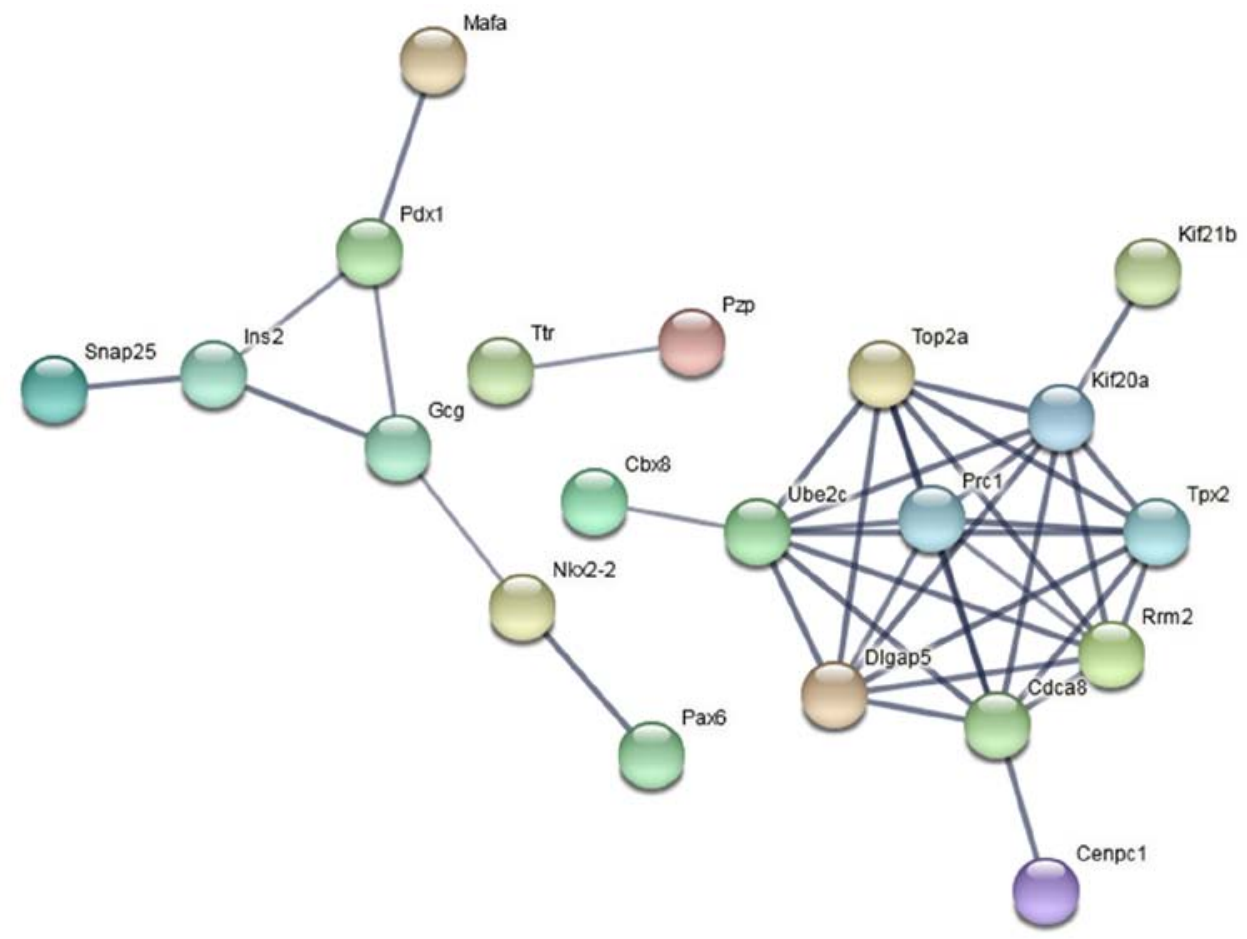

B

\begin{tabular}{|llcc|}
\hline \multicolumn{4}{c|}{ KEGG pathways } \\
\hline Pathway & Description & Count in gene set & False discovery rate \\
\hline mmu04950 & Maturity onset diabetes of the young & 5 of 27 & $2.00 \mathrm{e}-07$ \\
\hline$\underline{\mathrm{mmu04911}}$ & Insulin secretion & 4 of 85 & 0.00065 \\
\hline mmu04930 & Type II diabetes mellitus & 3 of 48 & 0.0022 \\
\hline
\end{tabular}

Figure 3. Protein-protein interaction analysis among downregulated proteins. (A) Protein-protein interaction and (B) signaling pathway analyses of downregulated proteins. KEGG, Kyoto Encyclopedia of Genes and Genomes.

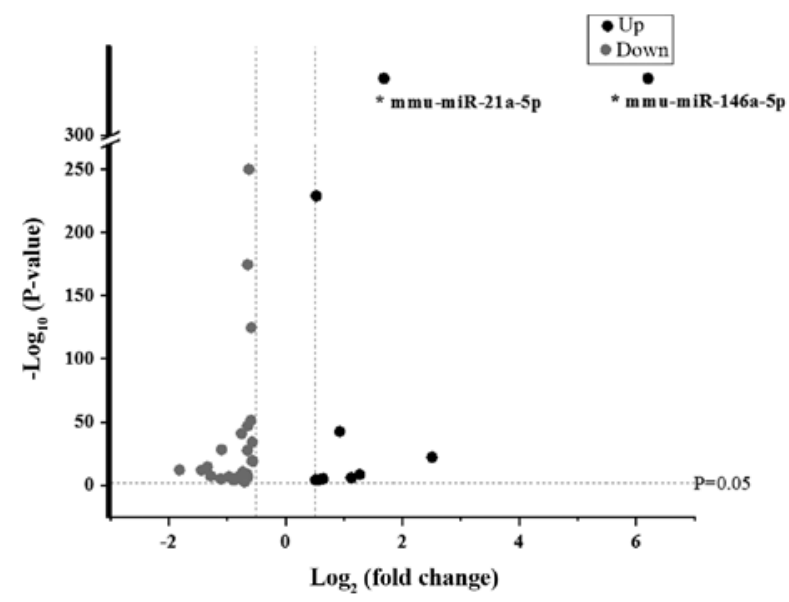

Figure 4. Volcano plot of upregulated and downregulated miRs in lipopolysaccharide-induced RAW264.7 cell medium-treated Beta-TC- 6 cells compared with controls. miR, microRNA; up, upregulated; down, downregulated; mmu, Mus musculus.

It was not clear whether upregulated miR-21a-5p and miR-146a-5p expression contributed to islet dysfunction. In the present study, the miR-21a-5p inhibitor was used to specifically inhibit the expression of miR-21a-5p in the miR-21a-5p inhibitor (decreased by 97\%; Fig. 6A) and the miR-21a-5p inhibitor+LRM groups (decreased by 99\%; Fig. 6B).
Additionally, the miR-146a-5p inhibitor was used to specifically inhibit the expression of miR-146a-5p in the miR-146a-5p inhibitor (decreased by 99\%; Fig. 6C) and miR-146a-5p inhibitor+LRM groups (decreased by 100\%; Fig. 6D).

After analyzing the expression of inflammatory factors, the results revealed that treatment with the miR-21a-5p or miR-146a inhibitor alone significantly increased the expression of IL-A and TNF- $\alpha$ when compared with the NC group (all, $\mathrm{P}<0.01$; Fig. $6 \mathrm{E}$ and F). However, following the induction of inflammation, the miR-21a-5p and miR-146a-5p inhibitor did not significantly affect the levels of each inflammatory factor when compared with the NC+LRM group (Fig. 6G and H). The results indicated that miR-21a-5p and miR-146a-5p may serve a minor role in the regulation of physiological inflammation homeostasis, but not in severe pathological inflammatory dysfunction.

As expected, LRM significantly decreased the mRNA expression of various islet functional factors when compared with the NC group, including Nkx-2.2 ( $\mathrm{P}<0.05)$, Gcg $(\mathrm{P}<0.05)$, Pax-6 $(\mathrm{P}<0.05)$, Snap25 $(\mathrm{P}<0.05), \mathrm{Pdx}-1 \quad(\mathrm{P}<0.01)$, Mafa $(\mathrm{P}<0.01)$ and Ins2 $(\mathrm{P}<0.01)$ (Fig. 7A). Additionally, it was revealed that miR-21a-5p inhibition significantly reversed the decrease in Nkx-2.2 $(\mathrm{P}<0.01)$, Mafa $(\mathrm{P}<0.01)$ and Ins2 $(\mathrm{P}<0.05)$ expression observed in the NC+LRM group (Fig. 7C). However, the miR-146 inhibitor did not exert the same effect (Fig. 7E). The results indicated that inflammation-induced miR-21a-5p 

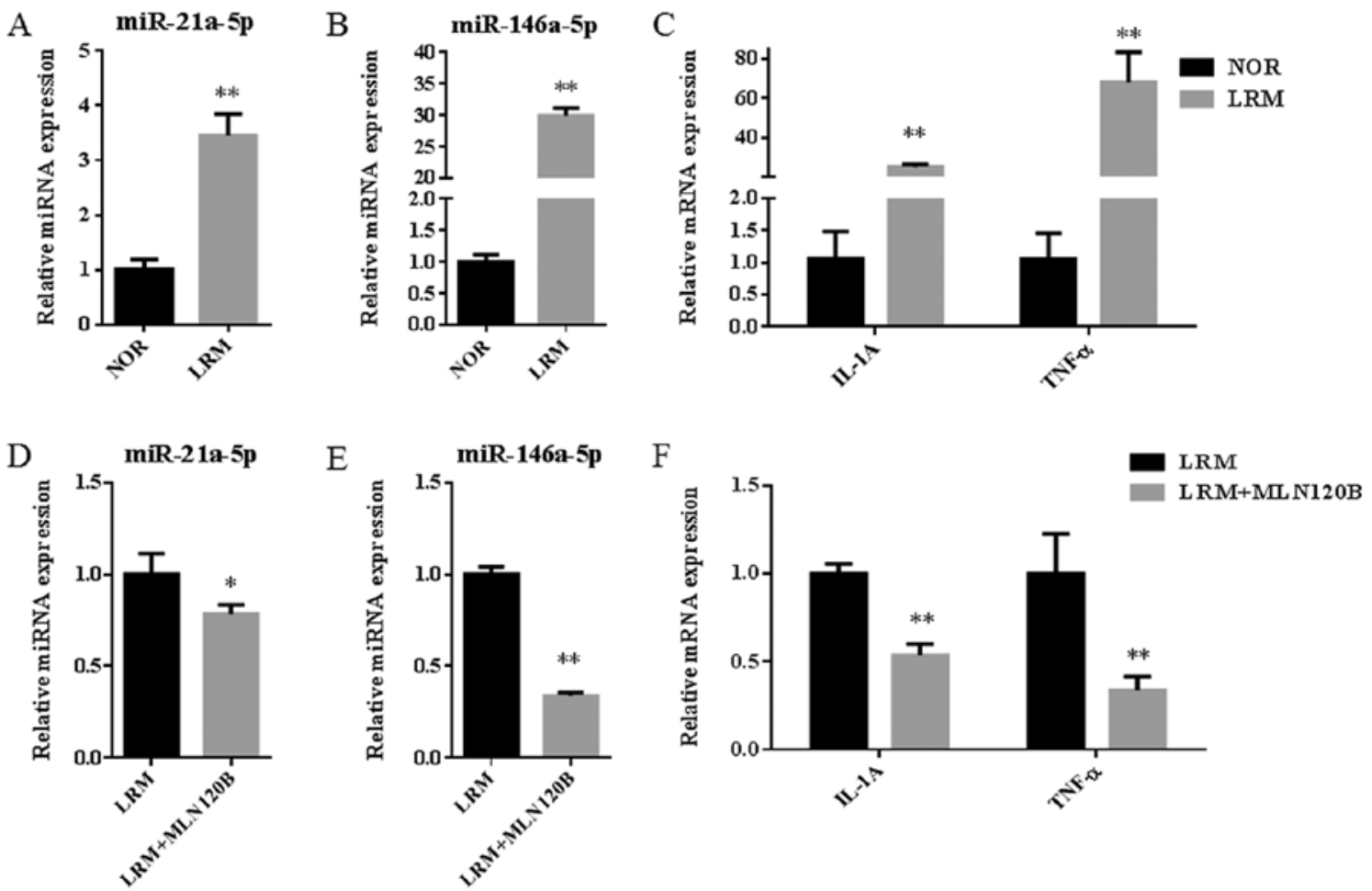

Figure 5. Relative expressions of microRNAs and inflammatory factors in the Beta-TC-6 cells treated with inflammatory stimulation and NF- $\mathrm{kB}$ pathway inhibition. Relative (A) miR-21a-5p and (B) miR-146a-5p expression in LRM-treated and untreated Beta-TC-6 cells. (C) Expression levels of IL-1A and TNF- $\alpha$ in LRM-treated and untreated Beta-TC-6 cells. Relative (D) miR-21a-5p and (E) miR-146a-5p expression in LRM-treated Beta-TC-6 cells after the addition of MLN120B. (F) Expression levels of IL-1A and TNF- $\alpha$ in LRM-treated Beta-TC-6 cells after the addition of MLN120B. Data are presented as the mean \pm SD $(\mathrm{n}=3)$. ${ }^{*} \mathrm{P}<0.05$ and ${ }^{* * *} \mathrm{P}<0.01$ vs. NOR or LRM. miRNA; microRNA; NOR, normal Beta-TC-6 cells; MLN120B, MLN120-treated Beta-TC-6 cells; LRM, LRM-treated Beta-TC-6 cells; LRM+MLN120B, MLN120B and LRM-treated Beta-TC-6 cells; LRM, lipopolysaccharide-induced macrophage cell medium.
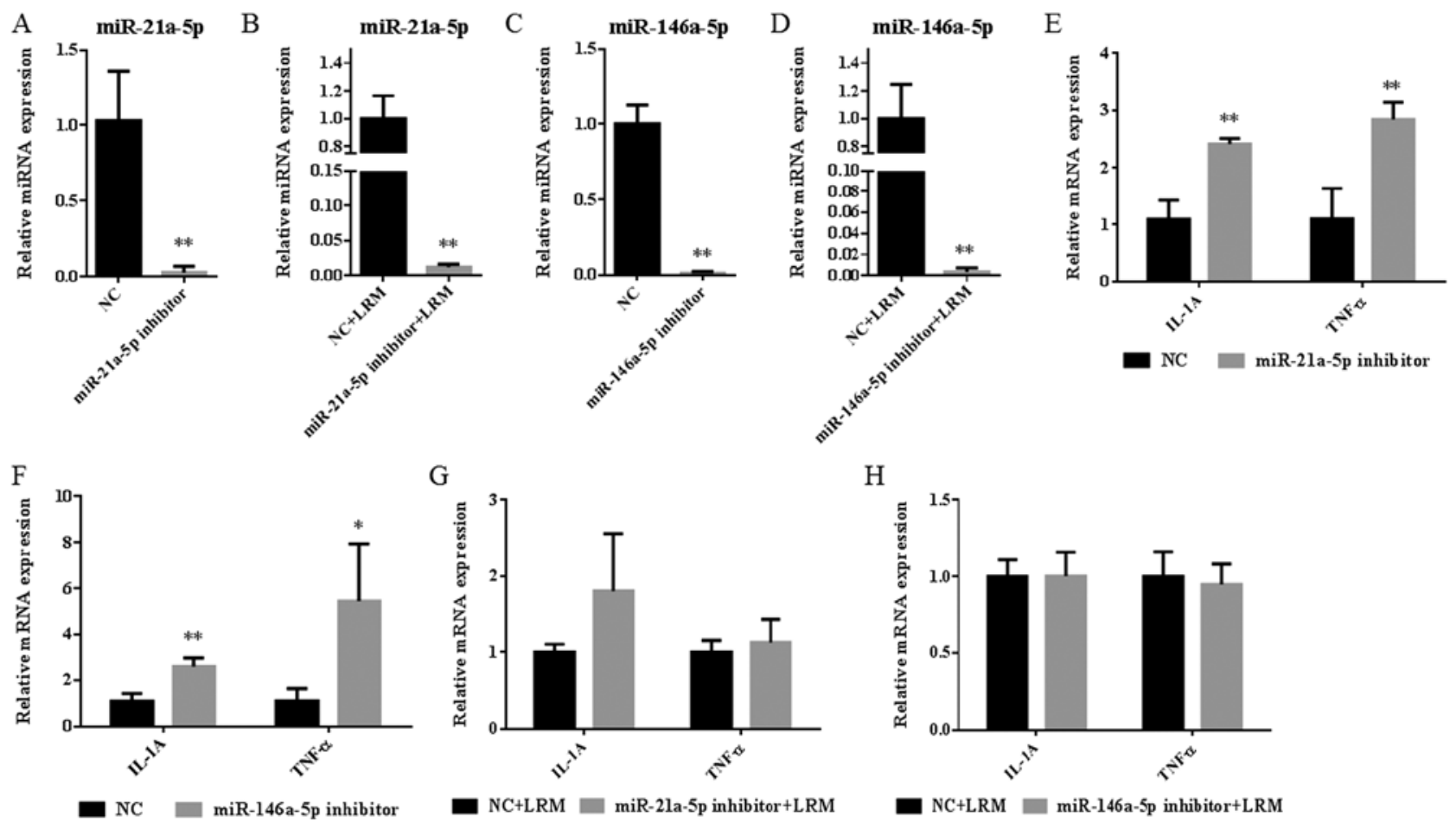

G
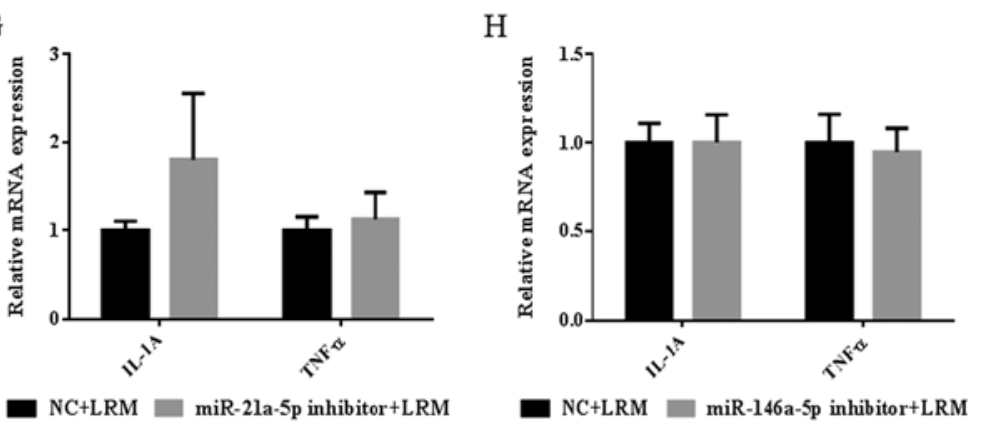

Figure 6. Relative expressions of miRNAs and inflammatory factors in the Beta-TC-6 cells after the addition of miR-21a-5p and miR-146a-5p inhibitors. Relative miR-21a-5p expression after the addition of the miR-21a-5p inhibitor in (A) Beta-TC-6 islet cells and (B) LRM-treated Beta-TC-6 islet cells. Relative miR-146a-5p expression after the addition of the miR-146a-5p inhibitor in (C) Beta-TC-6 islet cells and (D) LRM-treated Beta-TC-6 islet cells. Expression levels of IL-1A and TNF- $\alpha$ after the addition of the miR-21a-5p inhibitor in (E) Beta-TC-6 islet cells and (F) LRM-treated Beta-TC-6 islet cells. (G) Expression levels of IL-1A and TNF- $\alpha$ after the addition of the miR-146a-5p inhibitor in (G) Beta-TC-6 islet cells and (H) Beta-TC-6 islet cells. Data are presented as the mean $\pm \mathrm{SD}(\mathrm{n}=3)$. ${ }^{*} \mathrm{P}<0.05$ and ${ }^{* *} \mathrm{P}<0.01$ vs. NC. LRM+NC. miR, microRNA; LRM, lipopolysaccharide-induced macrophage cell medium; NC, negative control. 

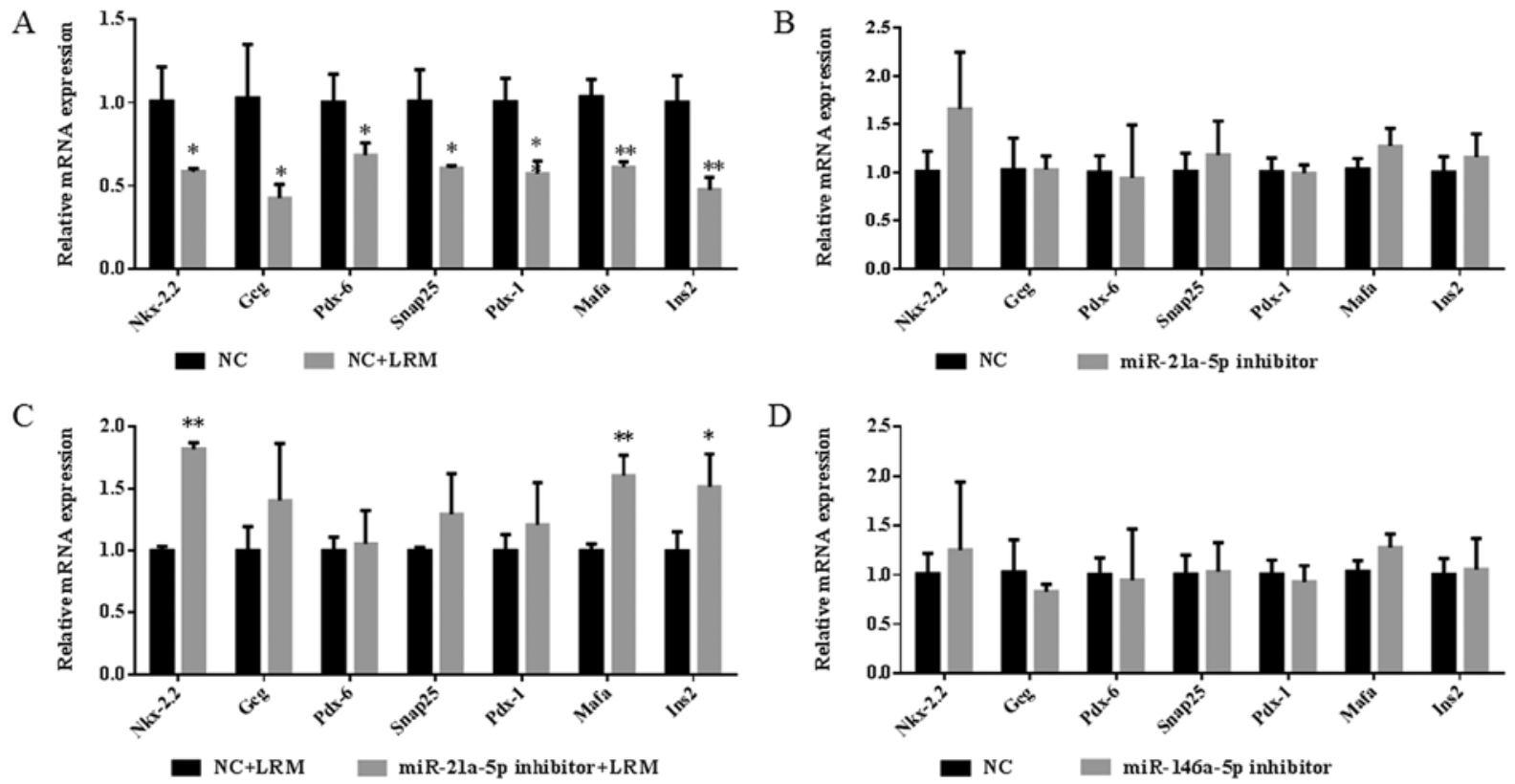

$\mathrm{D}$
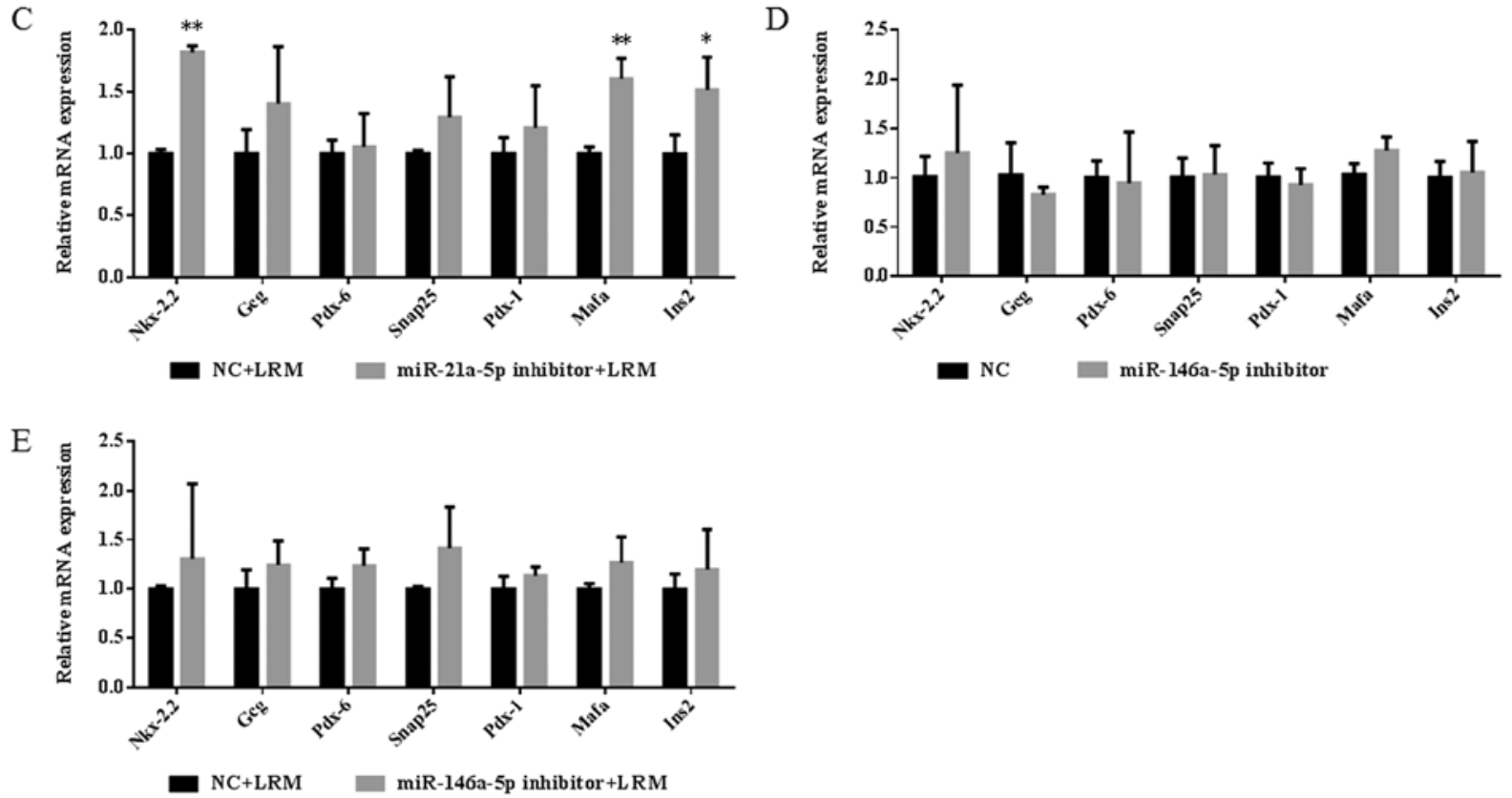

Figure 7. Expression of islet functional factors in Beta-TC-6 islet cells. (A) Expression of islet functional factors in LRM-treated and untreated Beta-TC-6 islet cells. (B-E) Expression levels of islet functional factors after the addition of inhibitors in LRM-treated and untreated Beta-TC-6 islet cells. $\mathrm{P}<0.05$ and ${ }^{* *} \mathrm{P}<0.01$ vs. NC or LRM+NC. Data are presented as the mean $\pm \mathrm{SD}(\mathrm{n}=3)$. LRM, lipopolysaccharide-induced macrophage cell medium; NC, negative control; miR, microRNA; Nkx-2.2, homeobox protein Nkx-2.2; Gcg, glucagon; Snap25, synaptosome-associated protein 25; Pdx-1, pancreatic and duodenal homeobox 1; Pax-6, paired box 6; Mafa, transcription factor MafA; Ins2, insulin-2.

expression may serve an important role in islet dysfunction. However, miR-146a-5p did not have a major effect in terms of reversing islet dysfunction factors, but may serve as a sensitive biomarker in islet cell inflammation.

\section{Discussion}

Although it is known that the pancreatic islet cells of patients with type 1 or 2 diabetes may be in a state of inflammation, no ideal in vitro islet cell model is available for humans (25). In addition, in preliminary experiments using LPS alone, Beta-TC- 6 cells could not be induced for evident inflammatory activation compared with LRM (data not shown). Considering that $>90 \%$ of patients with diabetes demonstrate the type 2 subtype and that macrophage cells accumulate in type 2 diabetic islets (26), the present study focused on the cross-talk between macrophages and islets. In the present study, LRM contained a large quantity of secreted inflammatory factors, and following collection, LRM was used to simulate the complicated microenvironment of inflammation around mouse pancreatic islet cells as previously described (10).

The proteomics assay of the present study revealed that inflammation induction by LRM downregulated the levels of key proteins associated with islet function, including Mafa, Pdx-1, Pax-6, Nkx-2.2, Gcg, Snap25 and Ins2, which mediate islet development and insulin secretion. Pdx-1 and Mafa are key transcription regulators of beta cell development and regeneration (27). Pax-6 is a transcription factor that has emerged as a key modulator of multiple steps in pancreatic development and differentiation, serving a pivotal role in the regulation of pancreatic islet hormone synthesis and secretion (28). Nkx-2.2 is a homeodomain transcription factor that is essential for the differentiation of three of the pancreatic endocrine populations: Alpha, beta and pancreatic polypeptide cells (29). The core proteins forming the SNARE complex are Snap25, vesicle-associated membrane protein and syntaxins (30), which primarily serve exocytotic functions (31). Snap25 is also associated with insulin secretion (32). Inflammation appears to affect insulin production by causing the loss of islet identity and inhibiting insulin secretion. The results of the present study determined the molecules involved in inflammatory dysfunction mechanisms and their pathological basis in islet cells. However, the exact mechanisms underlying the downregulation of these proteins remains unknown.

In humans, certain islet-specific miRNAs have been identified, including miR-375, miR-184, miR-183-5p, miR-182-5p 
and miR-127-3p (33). However, the function of the majority of miRNAs remain undetermined. Additionally, it has not yet been elucidated whether the function of the aforementioned miRNAs exhibit significant changes when subjected to inflammatory stimulation. In the present study, the miRNA assays revealed that inflammation promoted a large change in the miRNA profile of LRM-treated Beta-TC- 6 cells. These miRNAs (upregulated 11 and downregulated 28) may serve an important role in the pathological process of inflammatory dysfunction in islet cells. miR-21a-5p and miR-146a-5p may serve as effective targets due to their significant fold changes and high abundances observed following inflammatory stimulation in islet cells of the present study. Furthermore, miR-21a-5p and miR-146a-5p may be regulated by the NF- $\kappa B$ signaling pathway. miR-21 serves an important role in pro-inflammatory and anti-inflammatory responses (34). Whilst miR-21 targets Bcl-2 mRNA and promotes islet cell apoptosis (35), miR-21 silencing prolongs islet allograft survival by inhibiting Th17 cells (36). Furthermore, miR-21 promotes cardiac fibrosis after myocardial infarction by targeting smad7 (37). miR-21 has also emerged as a key mediator of the anti-inflammatory response, with inflammatory stimuli additionally triggering miR-21 induction (34). The present results indicated that miR-21a-5p could exert slight anti-inflammatory roles in a state of low-grade inflammation. miR-146a-5p serves as an important negative regulator of inflammation that can be upregulated by LPS (38). miR-21a-5p and miR-146a-5p appear to serve an important role in immune response tolerance or the homeostasis of inflammation stimulation $(10,39,40)$. In the present study, it was hypothesized that the upregulation of these miRNAs may affect islet function in addition to inflammatory regulation. However, this hypothesis requires further validation.

Using miRNA target prediction software (http:// c1.accurascience.com/miRecords/; updated April 27, 2013), it was revealed that miR-21a-5p and miR-146a-5p can target numerous genes. Although miR-21a-5p and miR-146a-5p may not directly regulate the aforementioned downregulated proteins, the proteins derived from their target genes may interact with them instead. It was suggested by authors that the upregulation of miR-21a-5p and miR-146a-5p may be involved in the downregulation of proteins associated with islet dysfunction induced by inflammation. Following mRNA validation, the downregulation of IL-1A and TNF- $\alpha$ was partially reversed in islets following treatment with an inhibitor of miR-21a-5p. However, the same affect was not induced following miR-146a-5p inhibitor treatment. Therefore, the regulatory mechanism underlying these miRNAs may be complex. Using an inhibitor of one miRNA may not be sufficient to validate its true function, since the cells exhibited a variety of changes in numerous miRNAs. It is possible that a single miRNA may only serve a limited role but likely exerts stronger effects when working in unison with other miRNAs. However, the coordinated function of all miRNAs with altered levels require further investigation. It may be necessary to converge all these altered miRNAs to validate their coordinated functions. However, it is very difficult to simultaneously reverse all downregulated or upregulated miRNAs in a single cellular system. Despite this, the results of the present study indicated that the upregulation of miR-21a-5p expression in inflammation may serve an important role in inflammatory islet dysfunction.
The present study provided valuable information regarding the altered expression of certain miRNAs and proteins. However, only the expression of two miRNAs and several mRNAs were validated. The remaining miRNAs and proteins involved should be further validated in future studies since other factors may be involved in the complex pathological system. Furthermore, primary or human islet cells should be investigated, as only one mouse islet cell line was utilized in the current study. In vivo experiments should be also be conducted in animals and humans to reflect true islet functions in the state of inflammation.

In conclusion, through proteomics and miRNA-omics, the present study drafted a complete profile of protein and miRNA changes that occur simultaneously in islet cells induced by inflammation, which may further the understanding of the underlying molecular mechanisms of diabetes and islet inflammation. miR-21a-5p and miR-146a-5p may serve as targets or biomarkers for inflammatory dysfunction in islet cells. Additionally, it was determined that these miRNAs were mediated via the NF- $\kappa B$ signaling pathway. Changes in proteins and miRNAs may form a large network to coordinate changes in islet cell functions in a pathological state. However, how miRNAs regulate target genes and proteins requires further investigation.

\section{Acknowledgements}

The authors would like to thank Mr. Pengbo Sun and Ms. Jingyi Luo (Shenzhen International Graduate School, Tsinghua University) for technical help when constructing volcano plots.

\section{Funding}

The present study was supported by the National Natural Science Foundation of China (grant nos. 81373460 and 91957110), the Natural Science Foundation of Guangdong Province (grant no. 2014A030313744) and the Shenzhen Science and Technology Innovation Committee (grant no. JC YJ20170307152357168).

\section{Availability of data and materials}

The datasets used and/or analyzed during the current study are available from the corresponding author on reasonable request.

\section{Authors' contributions}

$\mathrm{YD}, \mathrm{JZ}$ and $\mathrm{YW}$ performed the experiments. YD and $\mathrm{WX}$ analyzed the data. WX conceived the study and wrote the manuscript. All authors read and approved the final manuscript.

\section{Ethics approval and consent to participate}

Not applicable.

\section{Patient consent for publication}

Not applicable. 


\section{Competing interests}

The authors declare that they have no competing interests.

\section{References}

1. Wang L, Gao P, Zhang M, Huang Z, Zhang D, Deng Q, Li Y, Zhao Z, Qin X, Jin D, et al: Prevalence and ethnic pattern of diabetes and prediabetes in China in 2013. Jama 317: 2515-2523, 2017.

2. Lung CW, Wu FL, Liao F, Pu F, Fan Y and Jan YK: Emerging technologies for the prevention and management of diabetic foot ulcers. J Tissue Viability 29: 61-68, 2020.

3. Xie W and Du L: Diabetes is an inflammatory disease: Evidence from traditional Chinese medicines. Diabetes Obes Metab 13 289-301, 2011

4. Collier JJ, Sparer TE, Karlstad MD and Burke SJ: Pancreatic islet inflammation: An emerging role for chemokines. J Mol Endocrinol 59: R33-R46, 2017.

5. Morgan NG, Leete P, Foulis AK and Richardson SJ: Islet inflammation in human type 1 diabetes mellitus. IUBMB Life 66 : 723-734, 2014.

6. Mathis D, Vence L and Benoist C: Beta-Cell death during progression to diabetes. Nature 414: 792-798, 2001.

7. Lee RC, Feinbaum RL and Ambros V: The C. Elegans heterochronic gene lin-4 encodes small RNAs with antisense complementarity to lin-14. Cell 75: 843-854, 1993.

8. Zhao C, Zhang Y and Popel AS: Mechanistic computational models of MicroRNA-mediated signaling networks in human diseases. Int J Mol Sci 20: 421, 2019.

9. Ventriglia G, Nigi L, Sebastiani G and Dotta F: MicroRNAs: Novel players in the dialogue between pancreatic islets and immune system in autoimmune diabetes. Biomed Res Int 2015: 749734,2015

10. Jiang $\mathrm{X}, \mathrm{Xu} \mathrm{C}$, Lei F, Liao M, Wang W, Xu N, Zhang Y and Xie W: MiR-30a targets IL-1 $\alpha$ and regulates islet functions as an inflammation buffer and response factor. Sci Rep 7: 5270, 2017.

11. Wang ZK, Wang J, Liu J, Ying SH, Peng XJ and Feng MG: Proteomic and phosphoproteomic insights into a signaling hub role for $\mathrm{Cdc14}$ in asexual development and multiple stress responses in beauveria bassiana. PLoS One 11: e0153007, 2016.

12. Tyanova S, Temu T and Cox J: The maxQuant computational platform for mass spectrometry-based shotgun proteomics. Nat Protoc 11: 2301-2319, 2016.

13. Zhang H, Liu T, Zhang Z, Payne SH, Zhang B, McDermott JE, Zhou JY, Petyuk VA, Chen L, Ray D, et al: Integrated proteogenomic characterization of human high-grade serous ovarian cancer. Cell 166: 755-765, 2016.

14. Ross PL, Huang YN, Marchese JN, Williamson B, Parker K, Hattan S, Khainovski N, Pillai S, Dey S, Daniels S, et al: Multiplexed protein quantitation in saccharomyces cerevisiae using amine-reactive isobaric tagging reagents. Mol Cell Proteomics 3: 1154-1169, 2004.

15. Ouyang X, Jiang X, Gu D, Zhang Y, Kong SK, Jiang C and Xie W: Dysregulated serum MiRNA profile and promising biomarkers in dengue-infected patients. Int J Med Sci 13: 195-205, 2016.

16. Guan J, Long K, Ma J, Zhang J, He D, Jin L, Tang Q, Jiang A, Wang X, Hu Y, et al: Comparative analysis of the microRNA transcriptome between yak and cattle provides insight into high-altitude adaptation. PeerJ 5: e3959, 2017.

17. Langmead B, Trapnell C, Pop M and Salzberg SL: Ultrafast and memory-efficient alignment of short DNA sequences to the human genome. Genome Biol 10: R25, 2009.

18. Friedlander MR, Mackowiak SD, Li N, Chen W and Rajewsky N: MiRDeep2 accurately identifies known and hundreds of novel microRNA genes in seven animal clades. Nucleic Acids Res 40 37-52, 2012

19. Zhou L, Chen J, Li Z, Li X, Hu X, Huang Y, Zhao X, Liang C, Wang Y, Sun L, et al: Integrated profiling of microR NAs and mRNAs: MicroRNAs located on Xq27.3 associate with clear cell renal cell carcinoma. PLoS One 5: e15224, 2010.

20. Wang L, Feng Z, Wang X, Wang X, Zhang X and Zhang X: DEGseq: An R package for identifying differentially expressed genes from RNA-seq data. Bioinformatics 26: 136-138, 2010.
21. Storey JD: The positive false discovery rate: A Bayesian interpretation and the q-value. Ann Stat 31: 2013-2035, 2003

22. Hu X, Liu S, Liu X, Zhang J, Liang Y and Li Y: DPP-4 (CD26) inhibitor sitagliptin exerts anti-inflammatory effects on rat insulinoma (RINm) cells via suppressing NF- $\kappa \mathrm{B}$ activation. Endocrine 55: 754-763, 2017.

23. Xie W, Li M, Xu N, Lv Q, Huang N, He J and Zhang Y: MiR-181a regulates inflammation responses in monocytes and macrophages. PLoS One 8: e58639, 2013.

24. Livak KJ and Schmittgen TD: Analysis of relative gene expression data using real-time quantitative PCR and the 2(-Delta Delta C(T)) method. Methods 25: 402-408, 2001

25. Green AD, Vasu S and Flatt PR: Cellular models for beta-cell function and diabetes gene therapy. Acta Physiol (Oxf) 2018: 222, 2018

26. Eguchi $\mathrm{K}$ and Manabe I: 2013. Macrophages and islet inflammation in type 2 diabetes. Diabetes Obes Metab 15: 152-158, 2013.

27. Zhu Y, Liu Q, Zhou Z and Ikeda Y: PDX1, neurogenin-3, and MAFA: Critical transcription regulators for beta cell development and regeneration. Stem Cell Res Ther 8: 240, 2017.

28. Panneerselvam A, Kannan A, Mariajoseph-Antony LF and Prahalathan C: PAX proteins and their role in pancreas. Diabetes Res Clin Pract 155: 107792, 2019.

29. Sussel L, Kalamaras J, Hartigan-O'Connor DJ, Meneses JJ, Pedersen RA, Rubenstein JL and German MS: Mice lacking the homeodomain transcription factor $\mathrm{Nkx} 2.2$ have diabetes due to arrested differentiation of pancreatic beta cells. Development 125: 2213-2221, 1998

30. Cupertino RB, Kappel DB, Bandeira CE, Schuch JB, da Silva BS, Muller D, Bau CH and Mota NR: SNARE complex in developmental psychiatry: Neurotransmitter exocytosis and beyond. J Neural Transm (Vienna) 123: 867-883, 2016.

31. Shin $\mathrm{OH}$ : Exocytosis and synaptic vesicle function. Compr Physiol 4: 149-175, 2014.

32. Zhuang GQ, Wu W, Liu F, Ma JL, Luo YX, Xiao ZX, Liu Y, Wang W and He Y: SNAP-25(1-180) enhances insulin secretion by blocking Kv2.1 channels in rat pancreatic islet beta-cells. Biochem Biophys Res Commun 379: 812-816, 2009.

33. van de Bunt M, Gaulton KJ, Parts L, Moran I, Johnson PR, Lindgren CM, Ferrer J, Gloyn AL and McCarthy MI: The miRNA profile of human pancreatic islets and beta-cells and relationship to type 2 diabetes pathogenesis. PLoS One 8: e55272, 2013.

34. Sheedy FJ: Turning 21: Induction of miR-21 as a key switch in the inflammatory response. Front Immunol 6: 19, 2015.

35. Sims EK, Lakhter AJ, Anderson-Baucum E, Kono T, Tong X and Evans-Molina C: MicroRNA 21 targets BCL2 mRNA to increase apoptosis in rat and human beta cells. Diabetologia 60: 1057-1065, 2017.

36. Wang H, Fan H, Tao J, Shao Q and Ding Q: MicroRNA-21 silencing prolongs islet allograft survival by inhibiting Th17 cells. Int Immunopharmacol 66: 274-281, 2019.

37. Yuan J, Chen H, Ge D, Xu Y, Xu H, Yang Y, Gu M, Zhou Y, Zhu J, Ge T, et al: Mir-21 promotes cardiac fibrosis after myocardial infarction via targeting smad7. Cell Physiol Biochem 42: 2207-2219, 2017.

38. Nahid MA, Satoh M and Chan EK: Mechanistic role of microRNA-146a in endotoxin-induced differential cross-regulation of TLR signaling. J Immunol 186: 1723-1734, 2011.

39. Xie W, Li Z, Li M, Xu N and Zhang Y: MiR-181a and inflammation: MiRNA homeostasis response to inflammatory stimuli in vivo. Biochem Biophys Res Commun 430: 647-652, 2013.

40. Zhang S, Gu D, Ouyang X and Xie W: Proinflammatory effects of the hemagglutinin protein of the avian influenza A (H7N9) virus and microRNAmediated homeostasis response in THP1 cells. Mol Med Rep 12: 6241-6246, 2015.

This work is licensed under a Creative Commons Attribution-NonCommercial-NoDerivatives 4.0 International (CC BY-NC-ND 4.0) License. 